\title{
Association between an IGF-I gene polymorphism and body fatness: differences between generations
}

\author{
Paul G Voorhoeve, Elisabeth F C van Rossum ${ }^{1}$, Saskia J te Velde ${ }^{2}$, Jan W Koper ${ }^{1}$, Han C G Kemper ${ }^{2}$, \\ Steven W J Lamberts ${ }^{1}$ and Henriette A Delemarre-van de Waal $^{3}$ \\ Department of Pediatric Endocrinology, Canisius-Wilhelmina Hospital, PO Box 9015, 6500 GS Nijmegen, The Netherlands, ${ }^{1}$ Department of Internal \\ Medicine, Erasmus MC, Rotterdam, The Netherlands, ${ }^{2}$ Institute for Research in Extramural Medicine, VU University Medical Centre, Amsterdam, \\ The Netherlands and ${ }^{3}$ Department of Pediatric Endocrinology, VU University Medical Centre,Amsterdam, The Netherlands \\ (Correspondence should be addressed to P G Voorhoeve; Email: p.voorhoeve@cwz.nl)
}

(P G Voohoeve, E F C van Rossum and S J te Velde contributed equally to this work)

\begin{abstract}
Objective: A polymorphism near the promoter region of the IGF-I gene has been associated with serum IGF-I levels, body height and birth weight. In this study, we investigated whether this polymorphism is associated with body composition in young healthy subjects in two cohorts of different generations. Design: Observational study with repeated measurements.

Methods: The study group consisted of two comparable young Dutch cohorts with a generational difference of around 20 years. The older cohort consisted of 359 subjects born between 1961 and 1965. Measurements were performed from 13 until 36 years of age. The younger cohort consisted of 258 subjects born between 1981 and 1989. Measurements were performed from 8 until 14 years of age. Height, body mass index (BMI), fat mass, fat-free mass, waist and hip circumference were compared between wild-type carriers and variant type carriers of the IGF-I polymorphism.

Results: In the younger cohort, body weight, BMI, fat mass and waist circumference were significantly higher in female variant carriers of the IGF-I polymorphism. A similar trend was observed in male variant carriers. In contrast, these differences were not observed in the older cohort. Irrespective of genotype, the younger cohort showed a significantly higher total fat mass, body weight and BMI compared with the older cohort.

Conclusions: Because the differences between both genotypes were small, it seems likely that the genetic variability due to this IGF-I polymorphism impacts only slightly on body composition. Importantly, our study suggested that associations between this IGF-I promoter polymorphism and body composition possibly reflect a gene-environmental interaction of this polymorphism and that an environment that promotes obesity leads to a slightly more pronounced fat accumulation in variant carriers of this IGF-I polymorphism.
\end{abstract}

European Journal of Endocrinology 154 379-388

\section{Introduction}

Insulin-like growth factor (IGF)-I is a peptide that plays an important stimulatory role in skeletal growth, cell differentiation and metabolism. It is also known to influence body composition (1).

Recently, a polymorphism in the promotor region of the IGF-I gene which is associated with IGF-I serum levels, birth weight and body height in adults has been identified $(2,3)$. This polymorphism consists of a highly polymorphic microsatellite composed of variable cytosineadenosine (CA) repeats situated in the promotor region $1 \mathrm{~kb}$ upstream from the transcription site of IGF-I. The number of CA repeats ranges between 10 and 24, with the most common allele containing 19 CA repeats in the Caucasian population. There is a functional relationship between this polymorphism and circulating IGF-I levels. Carriers of the $192 \mathrm{bp}$ allele (19 CA repeats) and/or $194 \mathrm{bp}$ allele (20 CA repeats) of the IGF-I promoter have higher circulating IGF-I levels than non-carriers of these alleles (4). More importantly, non-carriers of the $192 \mathrm{bp}$ allele show an increased risk of type 2 diabetes and myocardial infarction (2). Although these findings have not always been confirmed by others (5), these observations may lead to the conclusion that genetically determined low IGF-I levels might play a role in the pathogenesis of these diseases.

Unfavourable body composition, such as high body mass index (BMI) and raised waist-to-hip ratio (WHR), is also associated with an increased risk for the development of type 2 diabetes and cardiovascular disease. Earlier studies, though, did not show a relation 
between this IGF-I gene polymorphism and body composition in the elderly (2).

As we know from recent epidemiological studies, the prevalence of overweight and obesity in adults and children is increasing worldwide, especially in the socalled Western countries $(6,7)$. The prevalence of overweight and obesity in children has also increased in The Netherlands $(8-10)$. This trend towards obesity seems to be primarily related to a changed lifestyle as a result of changed environmental and socio-economic factors and will undoubtedly lead to an increased morbidity and mortality at a younger age because of an expected sharp rise in the prevalence of type 2 diabetes mellitus and cardiovascular diseases (11-16). Besides environmental factors, genetic factors may also play a role. But apart from a few rare mutations leading to extreme obesity, no major genes have been found to be responsible for the increase in the prevalence of overweight or obesity.

In order to investigate the gene-environmental interaction, we examined the relationship between the polymorphism in the promoter region of the IGF-I gene and body composition in two comparable young Dutch cohorts from different birth cohorts with an age difference of approximately 15-25 years.

\section{Subjects and methods}

\section{Subjects}

The study group consists of two comparable young Dutch cohorts with a generational difference of about 20 years. The first and older cohort is the Amsterdam Growth and Health Longitudinal Study (AGAHLS) cohort, an observational study with repeated measurements $(17,18)$. Subjects were recruited from several schools in the city of Amsterdam. For the purpose of this study, only Caucasian and apparently healthy subjects were included. Measurements were performed at the mean ages of 12.9 (1st), 14.0 (2nd), 15.0 (3rd), 16.0 (4th) and 36.0 years of age (Table 1). The years of birth varied from 1961 to 1965 . From a total of 359 subjects (169 male and 190 female) we have complete data on IGF-I genotype and anthropometry of at least one of five time-points. The second and younger cohort is the Bone Study around Amsterdam in Kids (Bonestaak) cohort. In this study also, only Caucasian and apparently healthy subjects were included. The children were recruited from a number of primary and secondary schools in villages around Amsterdam. Measurements were performed at the mean ages of 10.7 (1st), 11.2 (2nd), 11.7 (3rd) and 12.6 (4th) years for the girls and at 11.7 (1st), 12.3 (2nd), 12.7 (3rd) and 13.6 (4th) years for the boys (Table 2). The years of birth varied from 1981 to 1987 for the girls and 1983 to 1989 for the boys. From a total of 258 subjects (132 male and 126 female) we have complete data on IGF-I genotype and anthropometry of at least one of four time-points.
Age distribution differed slightly between both cohorts but, as shown in Fig. 1, the overlap was considerable. Both cohorts were recruited in socioeconomically comparable areas and schools.

At each visit, height, weight and skin fold thickness were measured. Hip circumference and waist circumference were measured at each visit in the Bonestaak cohort, but only at 36 years of age in the AGAHLS cohort. In the AGAHLS cohort, yearly X-rays of the left hand were performed as a measure of bone age development. In the Bonestaak cohort, an X-ray of the left hand was performed at the first visit, and pubertal development (Tanner stages) was measured at each visit. Blood samples were collected for DNA analyses from all participants.

The study protocols were approved by the Committee of Ethics on Human Research of the VU University Medical Centre. All subjects and at least one of their parents gave their written informed consent.

\section{Anthropometric measurements}

Standing height and body weight were measured using a stadiometer and a calibrated scale respectively whilst wearing only underwear. BMI was calculated as body weight divided by body height squared. Waist (at umbilicus height) and hip circumference were measured using a flexible steel tape to the nearest $0.1 \mathrm{~cm}$. Body fat distribution was assessed by the WHR. Fat mass was estimated from four skin folds (biceps, triceps, subscapular and supra iliacal) using the equation of Durnin and Womersley $(19,20)$. These four skin folds were measured according to standard procedures (21). Fat-free mass was calculated by subtracting the fat mass from the body weight.

As interindividual variations in skin fold measurements in both cohorts were not measured, it is not possible to give exact data on the comparability of the skin fold measurements between both cohorts. Interaction analysis was performed to determine differences in the relation between fat mass and height, weight and BMI in both cohorts. These analyses showed significant differences which might indicate measurement variations between the two cohorts, but could also be contributed to by differences in body composition between the two cohorts. Within both cohorts, skin fold measurements were performed by the same investigators. Because differences between genotypes were analyzed within (and not between) both cohorts in this study, possible measurement variations between both cohorts could not influence the associations within both cohorts.

In the Bonestaak cohort, pubertal stage was recorded by visual assessment by a trained observer, using breast stages according to Tanner (B1-5) in girls or genital stages (G1-5) in boys.

Plain radiographs of the left hand and wrist in the AGAHLS cohort were made using a double wrapped Osray T-4 (Agfa-Gevaert, Mortsel, Belgium) film, with 
Table 1 Baseline characteristics and anthropometric parameters in the older cohort (AGAHLS) during adolescence and at the age of 36 years separately for males and females in IGF-I wild-type (WT) and variant carriers (VC).

\begin{tabular}{|c|c|c|c|c|c|c|c|c|c|c|c|c|c|c|c|c|c|c|c|c|c|}
\hline \multirow[b]{3}{*}{ Measurement } & & \multicolumn{4}{|c|}{ 1st } & \multicolumn{4}{|c|}{ 2nd } & \multicolumn{4}{|c|}{ 3rd } & \multicolumn{4}{|c|}{ 4th } & \multicolumn{4}{|c|}{36 years } \\
\hline & & \multicolumn{2}{|c|}{ Boys } & \multicolumn{2}{|c|}{ Girls } & \multicolumn{2}{|c|}{ Boys } & \multicolumn{2}{|c|}{ Girls } & \multicolumn{2}{|c|}{ Boys } & \multicolumn{2}{|c|}{ Girls } & \multicolumn{2}{|c|}{ Boys } & \multicolumn{2}{|c|}{ Girls } & \multicolumn{2}{|c|}{ Men } & \multicolumn{2}{|c|}{ Women } \\
\hline & & Mean & S.E. & Mean & S.E. & Mean & S.E. & Mean & S.E. & Mean & S.E. & Mean & S.E. & Mean & S.E. & Mean & S.E. & Mean & S.E. & Mean & S.E. \\
\hline \multirow[t]{2}{*}{ Number } & WT & 117 & & 123 & & 92 & & 113 & & 91 & & 110 & & 88 & & 115 & & 117 & & 133 & \\
\hline & VC & 45 & & 50 & & 41 & & 47 & & 41 & & 47 & & 43 & & 46 & & 50 & & 56 & \\
\hline \multirow[t]{2}{*}{ Age (years) } & WT & 12.9 & 0.06 & 12.9 & 0.05 & 14.0 & 0.06 & 14.0 & 0.06 & 15.0 & 0.06 & 15.0 & 0.06 & 16.0 & 0.06 & 16.0 & 0.05 & 36.0 & 0.07 & 36.1 & 0.06 \\
\hline & VC & 12.9 & 0.09 & 13.0 & 0.08 & 13.9 & 0.1 & 14.0 & 0.09 & 14.9 & 0.09 & 15.0 & 0.09 & 16.0 & 0.1 & 16.0 & 0.09 & 36.0 & 0.11 & 36.1 & 0.1 \\
\hline \multirow{2}{*}{ Height (cm) } & WT & $158^{*}$ & 0.7 & 160 & 0.7 & 166 & 0.9 & 164 & 0.6 & 174 ** & 0.9 & 167 & 0.6 & $178^{\star \star *}$ & 0.8 & 169 & 0.5 & 184.3 & 0.6 & 170.4 & 0.5 \\
\hline & VC & 157 & 1.3 & 161 & 1.2 & 164 & 1.4 & 165 & 1.1 & 172 & 1.3 & 169 & 1.0 & 176 & 1.1 & 170 & 1.0 & 182.8 & 1.0 & 170.1 & 0.9 \\
\hline \multirow[t]{2}{*}{ Weight (kg) } & WT & 42.7 & 0.5 & 45.7 & 0.8 & $48.8^{\star}$ & 0.7 & 50.3 & 0.7 & 55.5 & 0.8 & 54.0 & 0.7 & 61.1 & 0.8 & 56.8 & 0.7 & 84.3 & 1.0 & 67.6 & 0.9 \\
\hline & VC & 42.5 & 1.1 & 46.2 & 1.1 & 48.6 & 1.3 & 51.2 & 1.2 & 55.6 & 1.4 & 55.1 & 1.1 & 60.7 & 1.2 & 57.6 & 1.0 & 83.6 & 1.5 & 68.6 & 1.5 \\
\hline \multirow{2}{*}{ BMI $\left(\mathrm{kg} / \mathrm{m}^{2}\right)$} & WT & 17.0 & 0.1 & 17.8 & 0.2 & 17.6 & 0.1 & 18.5 & 0.2 & 18.3 & 0.1 & 19.3 & 0.2 & 19.1 & 0.2 & 19.9 & 0.2 & 24.8 & 0.3 & 23.3 & 0.3 \\
\hline & VC & 17.2 & 0.2 & 17.8 & 0.3 & 17.9 & 0.3 & 18.6 & 0.3 & 18.7 & 0.3 & 19.3 & 0.3 & 19.4 & 0.3 & 19.9 & 0.3 & 25.0 & 0.4 & 23.6 & 0.5 \\
\hline \multirow{2}{*}{ Fat mass $(\mathrm{kg})$} & WT & 6.8 & 0.2 & 11.2 & 0.3 & $7.5^{\star *}$ & 0.2 & 12.7 & 0.4 & 8.5 & 0.2 & 14.4 & 0.4 & 9.6 & 0.2 & 15.5 & 0.4 & 17.2 & 0.4 & 19.8 & 0.5 \\
\hline & VC & 7.0 & 0.4 & 11.0 & 0.4 & 8.0 & 0.4 & 12.9 & 0.5 & 9.2 & 0.5 & 14.5 & 0.5 & 10.2 & 0.5 & 15.5 & 0.5 & 17.6 & 0.7 & 20.1 & 0.8 \\
\hline \multirow[t]{2}{*}{ Fat-free mass (kg) } & WT & 35.9 & 0.4 & 34.5 & 0.5 & 41.3 & 0.6 & 37.5 & 0.4 & 46.9 & 0.7 & 39.6 & 0.4 & 51.5 & 0.7 & 41.2 & 0.4 & 66.9 & 0.7 & 47.7 & 0.5 \\
\hline & VC & 35.5 & 0.8 & 35.1 & 0.7 & 40.6 & 1.0 & 38.3 & 0.8 & 46.5 & 1.0 & 40.6 & 0.7 & 50.5 & 0.8 & 42.1 & 0.7 & 65.9 & 0.9 & 48.9 & 0.8 \\
\hline \multirow[t]{2}{*}{ Waist circ. (cm) } & WT & ND & & ND & & ND & & ND & & ND & & ND & & ND & & ND & & 85.5 & 0.7 & 73.1 & 0.8 \\
\hline & VC & ND & & ND & & ND & & ND & & ND & & ND & & ND & & ND & & 84.7 & 1.2 & 73.1 & 1.1 \\
\hline \multirow{2}{*}{ Hip circ. } & WT & ND & & ND & & ND & & ND & & ND & & ND & & ND & & ND & & 89.5 & 0.7 & 88.6 & 0.7 \\
\hline & VC & ND & & ND & & ND & & ND & & ND & & ND & & ND & & ND & & 88.6 & 1.0 & 89.2 & 1.3 \\
\hline \multirow[t]{2}{*}{ WHR } & WT & ND & & ND & & ND & & ND & & ND & & ND & & ND & & ND & & 0.96 & 0.0 & 0.83 & 0.01 \\
\hline & VC & ND & & ND & & ND & & ND & & ND & & ND & & ND & & ND & & 0.96 & 0.01 & 0.82 & 0.01 \\
\hline
\end{tabular}

$\mathrm{ND}$, not determined.

${ }^{*} P<0.1,{ }^{* *} P<0.05$ between genotypes WT and VC. 
Table 2 Baseline characteristics and anthropometric parameters in the younger cohort (Bonestaak) for boys and girls in IGF-I wild-type (WT) and variant carriers (VC).

\begin{tabular}{|c|c|c|c|c|c|c|c|c|c|c|c|c|c|c|c|c|c|}
\hline \multirow[b]{3}{*}{ Measurement } & & \multicolumn{4}{|c|}{ 1st } & \multicolumn{4}{|c|}{ 2nd } & \multicolumn{4}{|c|}{$3 r d$} & \multicolumn{4}{|c|}{ 4th } \\
\hline & & \multicolumn{2}{|c|}{ Boys } & \multicolumn{2}{|c|}{ Girls } & \multicolumn{2}{|c|}{ Boys } & \multicolumn{2}{|c|}{ Girls } & \multicolumn{2}{|c|}{ Boys } & \multicolumn{2}{|c|}{ Girls } & \multicolumn{2}{|c|}{ Boys } & \multicolumn{2}{|c|}{ Girls } \\
\hline & & Mean & S.E. & Mean & S.E. & Mean & S.E. & Mean & S.E. & Mean & S.E. & Mean & S.E. & Mean & S.E. & Mean & S.E. \\
\hline \multirow[t]{2}{*}{ Number } & WT & 98 & & 90 & & 98 & & 89 & & 97 & & 89 & & 77 & & 88 & \\
\hline & $\mathrm{VC}$ & 34 & & 36 & & 33 & & 36 & & 34 & & 36 & & 30 & & 36 & \\
\hline \multirow[t]{2}{*}{ Age (years) } & WT & 11.7 & 0.13 & 10.7 & 0.12 & 12.3 & 0.13 & 11.2 & 0.12 & 12.8 & 0.13 & 11.7 & 0.12 & 13.6 & 0.14 & 12.6 & 0.12 \\
\hline & vc & 11.7 & 0.22 & 10.7 & 0.2 & 12.2 & 0.23 & 11.2 & 0.2 & 12.7 & 0.22 & 11.7 & 0.2 & 13.7 & 0.23 & 12.6 & 0.2 \\
\hline \multirow{2}{*}{ Height $(\mathrm{cm})$} & WT & 153 & 1.0 & 147 & 0.9 & 156 & 1.1 & 150 & 0.9 & $160^{*}$ & 1.1 & 153 & 0.9 & 165 & 1.3 & 159 & 0.8 \\
\hline & vc & 155 & 1.8 & 148 & 1.9 & 158 & 1.9 & 150 & 1.9 & 162 & 2.1 & 154 & 1.9 & 167 & 2.1 & 158 & 1.8 \\
\hline \multirow{2}{*}{ Weight (kg) } & WT & 40.8 & 0.8 & 36.5 & 0.8 & 43. & 0.9 & $38.7^{\star *}$ & 0.8 & 46 & 0.9 & $41.5^{*}$ & 0.9 & $51.8^{*}$ & 1.1 & $46.2^{* *}$ & 9 \\
\hline & & 42.9 & 1.7 & & 1.4 & & 1.9 & 40.7 & 1. & 49 & 2.0 & 43.7 & 1. & 55.4 & 2.3 & & .7 \\
\hline \multirow{2}{*}{ BMI $\left(\mathrm{kg} / \mathrm{m}^{2}\right)$} & WT & 17.4 & 0.2 & $16.7^{* \star}$ & 0.2 & 17.8 & 0.2 & $17.0^{\star \star}$ & 0.2 & 18.0 & 0.2 & $17.5^{*}$ & 0.2 & 18.9 & 0.3 & $18.2^{\star}$ & 0.3 \\
\hline & vc & 17.7 & 0.5 & 17.4 & 0.4 & 18.3 & 0.5 & 17.8 & 0.4 & 18.5 & 0.5 & 18.4 & 0.5 & 19.6 & 0.6 & 18.9 & 0.4 \\
\hline \multirow{2}{*}{ Fat mass $(\mathrm{kg})$} & WT & 8.0 & 0.4 & $8.8^{\star \star *}$ & 0.4 & 8.4 & 0.4 & $9.4^{\star \star}$ & 0.5 & 8.8 & 0. & $10.1^{* \star}$ & 0.5 & 9.5 & 0.6 & $11.5^{*}$ & 0.5 \\
\hline & vc & 8.4 & 0.8 & 10.5 & 0.7 & 9.0 & 0.9 & 10.9 & 0.7 & 9.4 & 0. & 11.6 & 0.8 & 10.6 & 1.3 & 13.3 & 0.9 \\
\hline \multirow[t]{2}{*}{ Fat-free mass (kg) } & WT & $\begin{array}{l}0.4 \\
32.8\end{array}$ & 0.6 & 27.7 & 0.5 & 35.0 & 0.7 & 29.3 & 0.6 & 37.3 & 0.8 & 31.5 & 0.6 & $42.3^{*}$ & 1.0 & 34.7 & 0.6 \\
\hline & vc & 34.5 & 1.3 & 27 & 0.9 & 37.2 & 1.5 & 29.5 & 1.0 & 40.6 & 1.7 & 32. & 1. & 44.3 & 1.9 & 34 & 1.1 \\
\hline \multirow{2}{*}{ Waist circ. $(\mathrm{cm})$} & WT & 63.7 & 0.5 & $60.4^{* \star}$ & 0. & 65 & 0. & 62 & 0. & $65.8^{*}$ & 0. & $62.7^{* *}$ & 0. & $67.7^{* *}$ & 0.6 & $3^{3}$ & 0.7 \\
\hline & VC & & 1.1 & 63 & 1. & 6 & 1. & 63 & 0. & 68 & 1. & 64. & 1. & 70.4 & 1.3 & 66.8 & 1.5 \\
\hline \multirow{2}{*}{ Hip circ. (cm) } & W7 & 70 & 0.6 & & 0. & & 0. & * & 0 & & 0 & & 0. & 74 & 0.8 & & 0.8 \\
\hline & VC & 72.8 & 1.1 & 74.2 & 1.2 & 71.3 & 1.2 & 76.1 & 1.2 & 74.7 & 1.5 & 78.9 & 1.3 & 76.6 & 1.6 & 81.1 & 1.6 \\
\hline \multirow[t]{2}{*}{ WHR } & WT & 0.91 & 0.005 & 0.83 & 0.007 & 0.93 & 0.003 & 0.84 & 0.004 & 0.92 & 0.004 & 0.81 & 0.004 & 0.91 & 0.005 & 0.81 & 0.004 \\
\hline & VC & 0.90 & 0.007 & 0.85 & 0.016 & 0.94 & 0.006 & 0.84 & 0.006 & 0.91 & 0.007 & 0.82 & 0.007 & 0.92 & 0.006 & 0.82 & 0.009 \\
\hline
\end{tabular}

${ }^{*} P<0.1,{ }^{* *} P<0.05$ between genotypes WT and VC. 

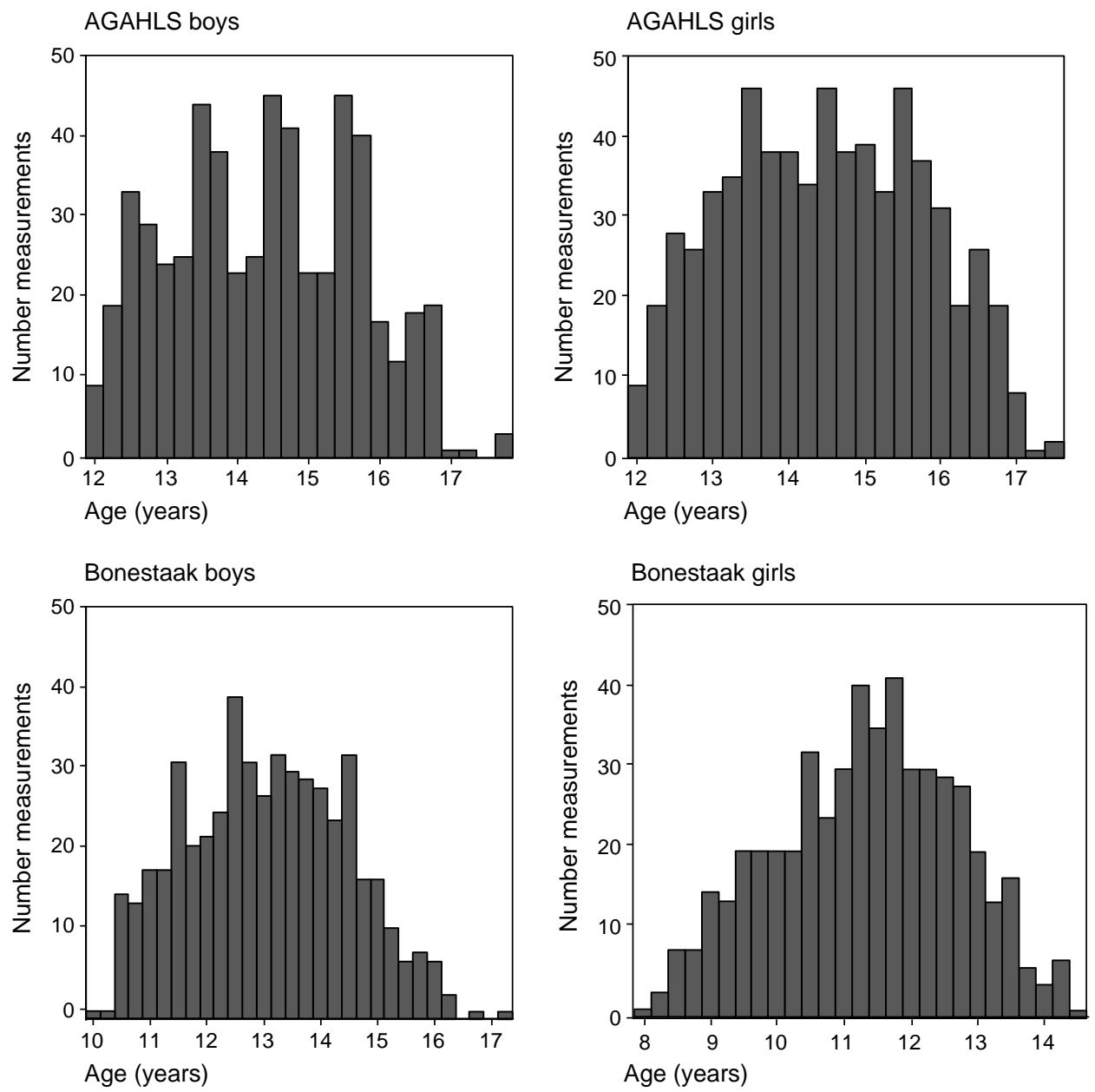

Figure 1 Distribution of numbers of measurements at given ages for the two cohorts.

an exposure time varying from 0.3 to $0.5 \mathrm{~s}$. Skeletal ages according to the Tanner-Whitehouse method were evaluated by one well-trained examiner.

To test for possible differences in sexual maturation between both cohorts, we compared differences in calendar age and bone age for subjects in both cohorts with overlapping ages. No statistical difference was found. For the Bonestaak cohort mean (calendar agebone age) \pm 1 S.D. $=0.18 \pm 1.1$ and for the AGAHLS cohort mean (calendar age-bone age) $=0.18 \pm 0.90$ $(P=0.98)$. This finding was in accordance with our national survey on pubertal development between 1965 and 1997, which showed that the timing of the occurrence of the various stages of pubertal development had stabilized between 1980 and 1997. This despite the general trend of increasing overweight and obesity in the same population (22).

\section{Genetic analyses}

Genotypes of the IGF-I polymorphism were determined as described earlier (2). In brief, DNA was isolated using standard methods. PCR was performed in a final volume of $10 \mu \mathrm{l}$ containing $10 \mathrm{ng}$ DNA, $10 \times$ Gold buffer (Perkin-Elmer Life and Analytical Sciences, Boston, MA, USA), 200-M dNTP, 30 pmol of each primer, $3 \mathrm{mM} \mathrm{MgCl} 2$, $0.5 \mathrm{U}$ Ampli Tag Gold polymerase (Perkin-Elmer). The PCR programme consisted of 30 cycles of $30 \mathrm{~s}$ at $95^{\circ} \mathrm{C}, 30 \mathrm{~s}$ at $55^{\circ} \mathrm{C}$ and $30 \mathrm{~s}$ at $72^{\circ} \mathrm{C}$ and additionally $5 \mathrm{~min}$ of denaturation at $95^{\circ} \mathrm{C}$ before the first cycle and an extension of $10 \mathrm{~min}$ at $72^{\circ} \mathrm{C}$ after the last cycle. Forward primers were labelled with FAM to determine the size of the PCR products by fragment analysis (ABI-Prism genetic analyzer with Genescan 2.1 software, Applied Biosystems, Nieuwerkerkaan den IJssel, The Netherlands). The Genescan 350/500 Tamra was used as internal size standard within the fragment analysis.

In earlier studies, carriers of the most frequent $192 \mathrm{bp}$ allele were defined as carriers, whereas all other variants were defined as non-carriers. Recent data have shown that subjects who were homozygous for the $194 \mathrm{bp}$ allele had IGF-I blood levels comparable with those who were homozygous for the $192 \mathrm{bp}$ allele 
(4). IGF-I levels were significantly lower in homozygous carriers of alleles with more than $194 \mathrm{bp}$ or less than $192 \mathrm{bp}$ in the IGF-I promoter region. Therefore, in contrast to earlier studies, in this study it was assumed that all subjects who were homozygous for $192 \mathrm{bp}$ or $194 \mathrm{bp}$ or were carrier of both the $192 \mathrm{bp}$ allele and the $194 \mathrm{bp}$ allele can be regarded as the wild-type group. Subsequently, all subjects who were carriers of at least one variant allele (either more than $194 \mathrm{bp}$ or less than $192 \mathrm{bp}$ ) are grouped as variant carriers. This more physiological classification was also used in two other recent studies $(23,24)$.

\section{Statistical analyses}

Data were analysed using SPSS for Windows, release 10.1 (SPSS, Chicago, IL, USA). Results are reported as means \pm S.E. Differences between genotypes were analysed using multiple regression analysis for boys and girls separately. Genotype was set as an independent variable, whereas height, weight, BMI, fat mass, fatfree mass, waist circumference and hip circumference were used as dependent variables. Adjustments for age, pubertal stage, bone age and weight were made, if appropriate, by putting these variables into different regression models. To investigate the influence of missing values on the statistics, analysis was performed on the complete dataset and on a truncated dataset of subjects without missing data.

In addition, longitudinal analyses were performed for the differences in IGF-I genotype, using linear generalized estimating equations (GEE) (25). GEEs take into account that the observations within each subject are correlated. By comparing analyses on different datasets it has been shown previously that GEE analyses behave very well in datasets with missing data when the outcome is a continuous variable (26). GEE analyses were performed with the Statistical Package for Interactive Data Analyses (27). As a result, regression coefficients which reflect the linear relationships between the predictor variable (i.e. genotype) and the outcome variables throughout the longitudinal period were estimated.

A statistical trend was defined as a $P$ value $\leq 0.1$. Statistical significance was set at $P \leq 0.05$.

\section{Results}

The overall difference in body composition between both cohorts, irrespective of genotype, was studied using regression analyses for the difference in fat mass, body weight and BMI. Results showed significantly higher fat mass, body weight and BMI in the younger cohort after adjustment for age and height where appropriate $(P<0.001)$.

Tables 1 and 2 show, separately for the older cohort (Table 1) and the younger cohort (Table 2), baseline characteristics and anthropometric parameters in wild-type and variant carriers of the IGF-I polymorphism at the different measurement time-points in boys and girls.

\section{Older cohort}

In the older cohort (AGAHLS), out of a total of 359 genotypings, we identified 106 (29.5\%) variant carriers of the IGF-I polymorphism (50 males and 56 females) (Table 1). The distribution of genotypes was in Hardy-Weinberg equilibrium $(P=0.27)$. Figure 2 shows graphically the differences in body composition estimates between genotypes at different time-points.

In males, we found greater body height in wild-type carriers at the age of 15 and 16 years $(P<0.05)$. At final height, these differences in height were no longer statistically significant. In females, no statistically significant differences in height were found between genotypes. No significant differences were found between the genotypes in both males and females for weight, BMI, fat mass and fat-free mass for nearly all measurements. Only in males at the age of 14 years was a significantly higher fat mass found in variant carriers of the IGF-I polymorphism $(P=0.04)$.

Waist circumference, hip circumference and calculated WHR were measured only at 36 years of age. No differences were found between genotypes at that age.

Using longitudinal analysis for all measurements, male wild-type carriers were $2 \mathrm{~cm}$ taller on average than variant carriers $(P=0.047)$. No differences were found between both genotypes for the other parameters in males as well as for all parameters in females (data not shown).

\section{Younger cohort}

In the younger cohort (Bonestaak) out of a total of 258 genotypes (of participants) we identified $70(27.1 \%)$ variant carriers of the IGF-I polymorphism (34 males and 36 females) (Table 2). The distribution of genotypes was in Hardy-Weinberg equilibrium in this group also $(P=0.15)$. Fig. 2 shows graphically the differences in body composition estimates between genotypes at different time-points.

In males, body height tended to be higher in variant carriers of the IGF-I polymorphism at the age of 13 years $(P=0.096)$. Differences in height between genotypes were not significant at other ages. No differences in height were found in females. Using longitudinal analysis for all measurements, male variant carriers were on average $4.8 \mathrm{~cm}$ taller than wild-type carriers $(P=0.013)$ after adjustment for age and pubertal stage. For females also, in longitudinal analysis no difference in height was found between genotypes.

In females, body weight tended to be or was significantly higher in variant carriers at all ages. In males, weight only tended to be higher in variant carriers at 
Old cohort (AGAHLS)
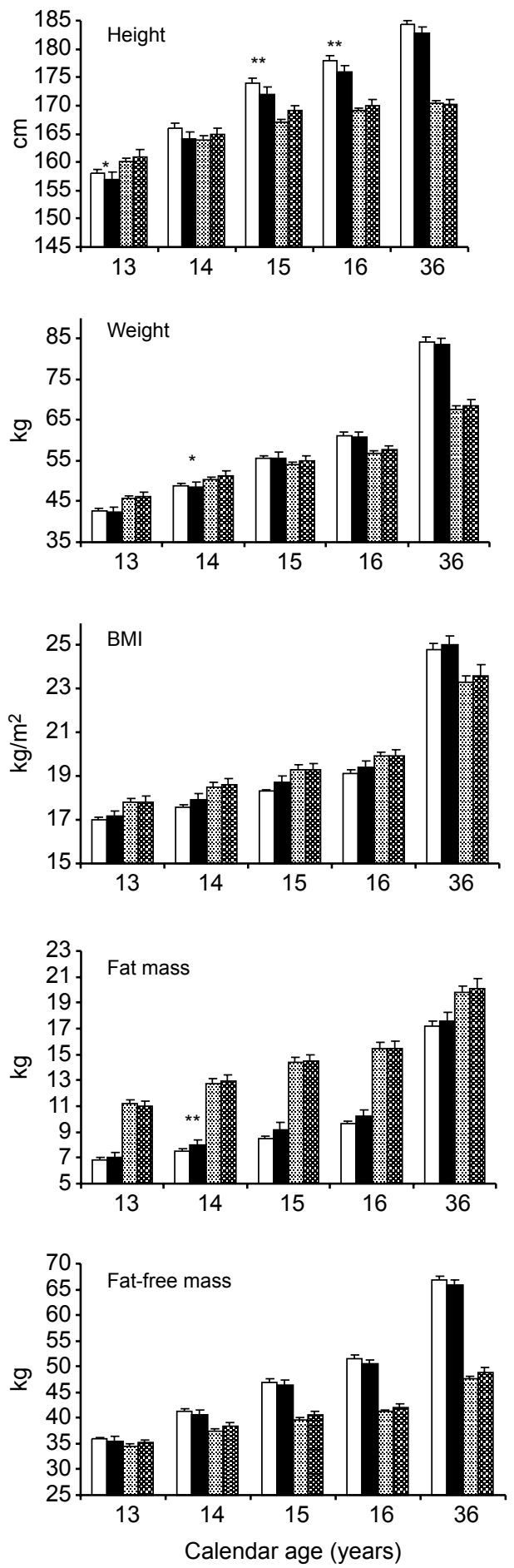

Young cohort (Bonestaak)
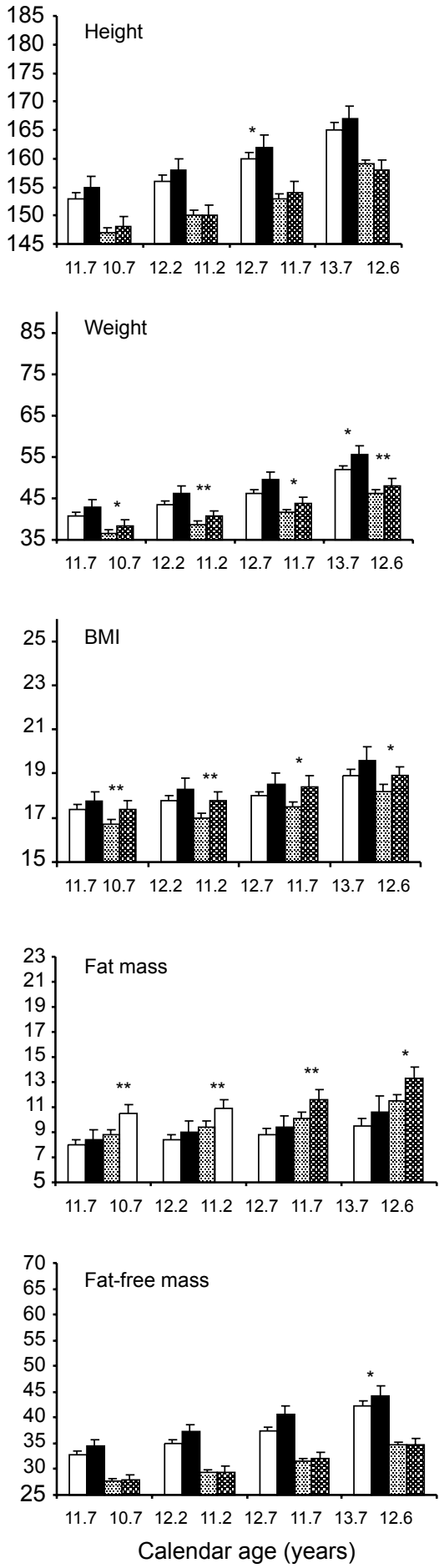

Figure 2 (Left) Body composition parameters in the older (AGAHLS) cohort at young $(13,14,15$ and 16 years) and adult (36 years) ages. (Right) Body composition parameters in the younger (Bonestaak) cohort (mean age 11.7, 12.2, 12.7, 13.7 years in boys and 10.7, 11.2, $11.7,12.6$ years in girls). Wild-type in boys (open bars), variant carrier in boys (solid bars), wild-type in girls (lightly shaded bars) and variant carrier in girls (darker shaded bars). Calculated differences are adjusted for bone age (AGAHLS cohort), pubertal stage (Bonestaak cohort) and age (and height in the case of weight, fat mass and fatfree mass) using regression analyses. ${ }^{\star} P<0.1,{ }^{\star \star} P<0.05$ between the wild-type and variant genotypes. Data are expressed as means \pm S.E.
14 years. Longitudinal analysis for weight at all timepoints showed higher body weight in male variant carriers $(\beta=5.06 \mathrm{~kg}, P=0.026)$ and female variant carriers $(\beta=2.1 \mathrm{~kg}, P=0.07)$ after adjustment for age and pubertal stage.
In addition, BMI tended to be or was significantly higher in female variant carriers at all ages. The same pattern was seen in males, but differences were not significant at any time-point. In longitudinal analyses, however, BMI tended to be higher in male variant 
carriers $\left(\beta=1.05 \mathrm{~kg} / \mathrm{m}^{2}, P=0.07\right)$ and was significantly higher in female variant carriers $(\beta=0.77$ $\left.\mathrm{kg} / \mathrm{m}^{2}, P=0.04\right)$.

Fat mass also tended to be or was significantly higher in female variant carriers at all ages. In longitudinal analysis this difference was also statistically significant $(\beta=1.31 \mathrm{~kg}, P=0.02)$. In males, this was not seen at the different time-points, but in longitudinal analyses a trend was seen towards higher fat mass in male variant carriers as well $(\beta=1.84 \mathrm{~kg}, P=0.09)$. Fat-free mass did not show any differences between genotypes in males and females.

Waist circumference was significantly higher in female variant carriers at the first $(P=0.024)$ and the third $(P=0.045)$ measurements (mean age 10.7 and 11.7 years). At the fourth measurement (mean age 12.6 years) waist circumference tended to be higher in variant carriers $(P=0.078)$. In males, waist circumference tended to be higher in variant carriers at the third measurement $(P=0.08)$ and was significantly higher at the fourth measurement $(P=0.04)$. In longitudinal analysis, waist circumference was significantly higher in female variant carriers $(\beta=2.0 \mathrm{~cm}, P=0.029)$ and tended to be higher in male variant carriers $(\beta=1.54 \mathrm{~cm}, P=0.077)$.

Hip circumference tended to be higher in male variant carriers at the first measurement $(P=0.065)$ and in female variant carriers at the second measurement $(P=0.067)$. In longitudinal analysis, a tendency towards greater hip circumference was only found in female variant carriers $(\beta=1.6 \mathrm{~cm}, P=0.051)$.

No differences in WHR were found between genotypes at any time-point or in longitudinal analysis.

Analyses of the truncated dataset, including only subjects who had complete data $(n=230)$ on all measurements, showed weaker results but the same trends were found (data not shown). That the results were less strong was to be expected because of loss of data and thus loss of statistical power.

\section{Discussion}

In this population-based cohort study, the associations between a polymorphism in the promoter region of the IGF-I gene and parameters of body composition and height were investigated in two young different birth cohorts of comparable origin and age. An important difference between the cohorts was a generational difference of about 20 years.

In the young Bonestaak cohort, body weight, BMI, fat mass, waist circumference and hip circumference were higher in female variant carriers of the IGF-I polymorphism. In boys, a similar trend towards higher weight, BMI, fat mass and waist circumference was also found in carriers of the variant IGF-I genotype. It seems unlikely that these differences between the genotypes are significant by chance because all the parameters tested (BMI, weight, fat mass, waist and hip circumference) represent more or less the same properties. The differences that were found all point in the same direction in the whole cohort, at all timepoints for both sexes. If significance was only reached by the number of tests performed, this would not be the case. These findings were also confirmed by longitudinal analyses.

The differences in body composition between genotypes were not observed in the older AGAHLS cohort. Differences in cohort size did not appear to be the explanation since the group size of the AGAHLS cohort was larger than the younger cohort. The only clear difference between genotypes in this cohort was found in male wild-type carriers of the IGF-I polymorphism who had higher standing height than variant carriers, which is in accordance with earlier findings in adults (2). This was in contrast to male wild-type carriers in the young Bonestaak cohort who were shorter than variant carriers. In addition, variant carriers in this cohort had a higher weight, which is not found in the old cohort. It is known that an increase in fat mass or BMI in childhood is associated with an increased height gain (28). Therefore, the finding of contrasting relationships between body height and genotype in the two separate cohorts can possibly be explained by the observation that in the younger cohort fat mass was higher in variant carriers of the IGF-I polymorphism, which may specifically diminish the influence of the polymorphism on growth.

As both groups were comparable with regard to socio-economic, geographic and genetic background, some other environmental factor might be responsible for the difference in body composition between the IGF-I genotypes in both study cohorts. As it is known from recent epidemiological studies that the prevalence of overweight and obesity in adults and children is increasing worldwide, especially in the so-called Western countries $(6,7)$, we studied the overall difference in body composition between both cohorts. Regression analyses of the difference in fat mass, body weight and BMI between both cohorts showed significantly higher fat mass, body weight and BMI in the younger cohort after adjustment for age and height where appropriate. Therefore it could be argued that, in contrast to the older cohort, the presence of an association between IGF-I genotype and body composition in the younger, and fatter cohort reflects a possible gene-environmental interaction of this polymorphism. Possibly an environment that promotes obesity leads to a more pronounced fat accumulation in variant carriers of this IGF-I polymorphism.

As is known from earlier studies, carriers of the variant IGF-I promoter have lower IGF-I levels than wildtype carriers (4). Although the beneficial effects of growth hormone on lean body mass and body fat are quite well known, conflicting results on the direct influence of IGF-I on body composition have been reported 
(29-35). Although IGF-I has no direct effects on adipocytes because of the lack of functional receptors in adipose tissue, it is known to enhance lipolysis by reducing insulin levels and thus releasing the brakes on lipolysis which, on theoretical grounds, could lead to less fat accumulation in wild-type carriers of this IGF-I polymorphism (36-40). Earlier studies on the same IGF-I polymorphism in elderly subjects did not show any differences in BMI and WHR between both genotypes $(2,41,42)$. These studies differed from our study in the slightly different way in that wild-type carrying and non-carrying of the IGF-I polymorphism were defined, as well as the age of the study groups. Subjects in other studies were all between 55 and 75 years of age, a cohort from an even older generation than our AGAHLS cohort, and who certainly did not live in an environment that promotes obesity like today's children. Since Vaessen et al. (2) found an increased risk for type 2 diabetes and myocardial infarction in non-carriers of the $192 \mathrm{bp}$ allele in these old cohorts, one could speculate that there is an increased risk of an earlier development of type 2 diabetes and cardiovascular disease for young individuals living in the present overweight-promoting environment and who are carriers of this polymorphism.

In conclusion, we found that carrying a genetic polymorphism in the promoter region of the IGF-I gene is associated with higher body weight, BMI, fat mass and waist circumference in young subjects. Because the differences found between both genotypes were small, it seems likely that the genetic variability due to this IGF-I polymorphism impacts only slightly on body composition in this cohort. These associations were not found in comparable young, but generally leaner, subjects of an older generation. We hypothesize that these differences possibly reflect a gene-environmental interaction of this polymorphism and that an environment that promotes obesity leads to a more pronounced fat accumulation in carriers of this IGF-I polymorphism. To test this hypothesis, future studies are needed in even younger or more obese cohorts.

\section{References}

1 Froesch ER, Hussain MA, Schmid C \& Zapf J. Insulin-like growth factor I: physiology, metabolic effects and clinical uses. Diabetes/Metabolism Reviews 199612 195-215.

2 Vaessen N, Heutink P, Janssen JA, Witteman JC, Testers L, Hofman A, Lamberts SW, Oostra BA, Pols HA \& van Duijn CM. A polymorphism in the gene for IGF-I: functional properties and risk for type 2 diabetes and myocardial infarction. Diabetes 2001 $\mathbf{5 0} 637-642$.

3 Vaessen N, Janssen JA, Heutink P, Hofman A, Lamberts SW, Oostra BA, Pols HA \& van Duijn CM. Association between genetic variation in the gene for insulin-like growth factor-I and low birthweight. Lancet $20023591036-1037$.

4 Rietveld I, Janssen JA, van Rossum EF, Houwing-Duistermaat JJ, Rivadeneira F, Hofman A, Pols HA, van Duijn CM \& Lamberts SW. A polymorphic CA repeat in the IGF-I gene is associated with gender-specific differences in body height, but has no effect on the secular trend in body height. Clinical Endocrinology 200461 195-203.

5 Frayling TM, Hattersley AT, McCarthy A, Holly J, Mitchell SM, Gloyn AL, Owen K, Davies D, Smith GD \& Ben Shlomo Y. A putative functional polymorphism in the IGF-I gene: association studies with type 2 diabetes, adult height, glucose tolerance, and fetal growth in U.K. populations. Diabetes 200251 2313-2316.

6 Obesity: preventing and managing the global epidemic. Report of a WHO consultation, World Health Organisation Technical Report Series $20008941-253$.

7 Cole TJ, Bellizzi MC, Flegal KM \& Dietz WH. Establishing a standard definition for child overweight and obesity worldwide: international survey. British Medical Journal $2000 \mathbf{3 2 0}$ $1240-1243$.

8 Seidell JC, Verschuren WM \& Kromhout D. Prevalence and trends of obesity in The Netherlands 1987-1991. International Journal of Obesity Related Metabolic Disorders 199519 924-927.

9 Fredriks AM, van Buuren S, Wit JM \& Verloove-Vanhorick SP. Body index measurements in 1996-1997 compared with 1980. Archives of Diseases in Childhood 200082 107-112.

10 Fredriks AM, van Buuren S, Hirasing RA, Wit JM \& VerlooveVanhorick SP. Alarming prevalences of overweight and obesity for children of Turkish, Moroccan and Dutch origin in The Netherlands according to international standards. Acta Paediatrica 200594 496-498.

11 Sinha R, Fisch G, Teague B, Tamborlane WV, Banyas B, Allen K, Savoye M, Rieger V, Taksali S, Barbetta G, Sherwin RS \& Caprio S. Prevalence of impaired glucose tolerance among children and adolescents with marked obesity. New England Journal of Medicine $2002346802-810$.

12 Freedman DS. Clustering of coronary heart disease risk factors among obese children. Journal of Pediatric Endocrinology and Metabolism 200215 1099-1108.

13 Freedman DS, Khan LK, Serdula MK, Galuska DA \& Dietz WH. Trends and correlates of class 3 obesity in the United States from 1990 through 2000. Journal of the American Medical Association $2002 \mathbf{2 8 8} 1758-1761$.

14 Freedman DS, Khan LK, Dietz WH, Srinivasan SR \& Berenson GS. Relationship of childhood obesity to coronary heart disease risk factors in adulthood: the Bogalusa Heart Study. Pediatrics 2001 $108712-718$.

15 Freedman DS, Dietz WH, Srinivasan SR \& Berenson GS. The relation of overweight to cardiovascular risk factors among children and adolescents: the Bogalusa Heart Study. Pediatrics 1999 103 1175-1182.

16 Freedman DS, Serdula MK, Srinivasan SR \& Berenson GS. Relation of circumferences and skinfold thicknesses to lipid and insulin concentrations in children and adolescents: the Bogalusa Heart Study. American Journal of Clinical Nutrition 199969 308-317.

17 Kemper HC, van Mechelen W, Post GB, Snel J, Twisk JW, van Lenthe FJ \& Welten DC. The Amsterdam Growth and Health Longitudinal Study. The past (1976-1996) and future (1997-?). International Journal of Sports Medicine $1997 \mathbf{1 8}$ (Suppl 3) S140-S150.

18 Kemper HCG (Ed). Amsterdam Growth and Health Longitudinal Study, A 23-year Follow-up from Teenager to Adult about Lifestyle and Health, In Medicine and Sport Science, vol. 47, pp 1-198, Eds. J Borms, M Hebbelinck \& A P Hills. Basel: Karger, 2004.

19 Durnin JV \& Rahaman MM. The assessment of the amount of fat in the human body from measurements of skinfold thickness. British Journal of Nutrition 196721 681-689.

20 Durnin JV \& Womersley J. Body fat assessed from total body density and its estimation from skinfold thickness: measurements on 481 men and women aged from 16 to 72 years. British Journal of Nutrition 197432 77-97.

21 Weiner JS. Human Biology, A Guide to Field Methods. International Biology Programme. Eds JS Weiner \& JA Lourie. Oxford: Edinburgh: Blackwell Scientific, 1969. 
22 Mul D, Fredriks AM, van Buuren S, Oostdijk W, VerlooveVanhorick SP \& Wit JM. Pubertal development in The Netherlands 1965-1997. Pediatric Research 2001 50 479-486.

23 Bleumink GS, Rietveld I, Janssen JA, van Rossum EF, Deckers JW, Hofman A, Witteman JC, van Duijn CM \& Stricker BH. Insulinlike growth factor-I gene polymorphism and risk of heart failure (the Rotterdam Study). American Journal of Cardiology 200494 384-386.

24 te Velde SJ, van Rossum EF, Voorhoeve PG, Twisk JW, Delemarre van de Waal HA, Stehouwer CD, van Mechelen W, Lamberts SW \& Kemper HC. An IGF-I promoter polymorphism modifies the relationships between birth weight and risk factors for cardiovascular disease and diabetes at age 36. BioMedCentral Endocrine Disorders $2005 \mathbf{5} 5$.

25 Diggle PJ, Liang KY \& Zeger SL. Analysis of Longitudinal Data. Oxford: Oxford University Press, 2002.

26 Twisk JW Missing data in longitudinal studies. In Applied Longitudinal Data Analysis for Epidemiology - A Practical Guide, pp 202-223. Cambridge UK: Cambridge University Press, 2003.

27 Gebski V, Leung O, McNeil D, Lunn D. SPIDA User Manual, version 6. Eastwood, Australia: Macquarie University NSW, 1992.

28 He Q \& Karlberg J. BMI in childhood and its association with height gain, timing of puberty, and final height. Pediatric Research $200149244-251$

29 Arnhold IJ, Oliveira SB, Osorio MG, Carrilho AJ, Nicolau W, Bianco AC \& Mendonca BB. Lack of reduction in body fat after treatment with insulin-like growth factor-I in two children with growth hormone gene deletions. Journal of Endocrinological Investigations $200023258-262$.

30 Backeljauw PF \& Underwood LE. Therapy for 6.5-7.5 years with recombinant insulin-like growth factor I in children with growth hormone insensitivity syndrome: a clinical research center study. Journal of Clinical Endocrinology and Metabolism 200186 1504-1510.

31 Mauras N, Martinez V, Rini A \& Guevara-Aguirre J. Recombinant human insulin-like growth factor I has significant anabolic effects in adults with growth hormone receptor deficiency: studies on protein, glucose, and lipid metabolism. Journal of Clinical Endocrinology and Metabolism 200085 3036-3042.

32 Mauras N, O’Brien KO, Welch S, Rini A, Helgeson K, Vieira NE \& Yergey AL. Insulin-like growth factor I and growth hormone $(\mathrm{GH})$ treatment in GH-deficient humans: differential effects on protein, glucose, lipid, and calcium metabolism. Journal of Clinical Endocrinology and Metabolism 200085 1686-1694.

33 Ranke MB, Savage MO, Chatelain PG, Preece MA, Rosenfeld RG \& Wilton P. Long-term treatment of growth hormone insensitivity syndrome with IGF-I. Results of the European Multicentre Study. The Working Group on Growth Hormone Insensitivity Syndromes. Hormone Research 199951 128-134.

34 Shaw NJ, Fraser NC, Rose S, Crabtree NJ \& Boivin CM. Bone density and body composition in children with growth hormone insensitivity syndrome receiving recombinant IGF-I. Clinical Endocrinology $2003 \mathbf{5 9} 487-491$.

35 Woods KA, Camacho-Hubner C, Bergman RN, Barter D, Clark AJ \& Savage MO. Effects of insulin-like growth factor I (IGF-I) therapy on body composition and insulin resistance in IGF-I gene deletion. Journal of Clinical Endocrinology and Metabolism $2000 \mathbf{8 5}$ 1407-1411.

36 Leahy JL \& Vandekerkhove KM. Insulin-like growth factor-I at physiological concentrations is a potent inhibitor of insulin secretion. Endocrinology 1990126 1593-1598.

37 Guler HP, Schmid C, Zapf J \& Froesch ER. Effects of recombinant insulin-like growth factor I on insulin secretion and renal function in normal human subjects. PNAS $1989 \mathbf{8 6} 2868-2872$.

38 Zenobi PD, Graf S, Ursprung H \& Froesch ER. Effects of insulin-like growth factor-I on glucose tolerance, insulin levels, and insulin secretion. Journal of Clinical Investigation 199289 1908-1913.

39 Rennert NJ, Caprio S \& Sherwin RS. Insulin-like growth factor I inhibits glucose-stimulated insulin secretion but does not impair glucose metabolism in normal humans. Journal of Clinical Endocrinology and Metabolism 199376 804-806.

40 Hussain MA, Schmitz O, Mengel A, Keller A, Christiansen JS, Zapf J \& Froesch ER. Insulin-like growth factor I stimulates lipid oxidation, reduces protein oxidation, and enhances insulin sensitivity in humans. Journal of Clinical Investigation 199392 2249-2256.

41 Rietveld I, Janssen JA, Hofman A, Pols HA, van Duijn CM \& Lamberts SW. A polymorphism in the IGF-I gene influences the age-related decline in circulating total IGF-I levels. European Journal of Endocrinology $2003 \mathbf{1 4 8} 171-175$.

42 Schut AFC, Janssen JAMJ, Deinum J, Vergeer JM, Hofman A, Lamberts SWJ, Oostra BA, Pols HAP, Witteman JCM \& van Duijn CM. Polymorphism in the promoter region of the insulin-like growth factor I gene is related to carotid intima-media thickness and aortic pulse wave velocity in subjects with hypertension. Stroke $2003341623-1627$.

Received 29 August 2005

Accepted 24 November 2005 